\title{
Intestinal epithelial cells promote colitis-protective regulatory T-cell differentiation through dendritic cell conditioning
}

\author{
ID Iliev $^{1}$, E Mileti $^{1}$, G Matteoli $^{1}$, M Chieppa $^{1}$ and M Rescigno $^{1}$
}

Intestinal dendritic cells (DCs) have been shown to display specialized functions, including the ability to promote gut tropism to lymphocytes, to polarize noninflammatory responses, and to drive the differentiation of adaptive Foxp3 ${ }^{+}$ regulatory $T\left(T_{\text {reg }}\right)$ cells. However, very little is known about what drives the mucosal phenotype of DCs. Here, we present evidence that the local microenvironment, and in particular intestinal epithelial cells (ECs), drive the differentiation of $\mathrm{T}_{\text {reg }}$-cell-promoting DCs, which counteracts Th1 and Th17 development. EC-derived transforming growth factor- $\beta$ (TGF- $\beta$ ) and retinoic acid (RA), but not thymic stromal lymphopoietin (TSLP), were found to be required for DC conversion. After EC contact, DCs upregulated CD103 and acquired a tolerogenic phenotype. EC-conditioned DCs were capable of inducing de novo $\mathrm{T}_{\text {reg }}$ cells with gut-homing properties that when adoptively transferred, protected mice from experimental colitis. Thus, we have uncovered an essential mechanism in which EC control of DC function is required for tolerance induction.

\section{INTRODUCTION}

The symbiosis between commensal bacteria and the gut has risks and benefits for the host organism because bacteria continuously challenge the fine balance of intestinal immune homeostasis with their cargo of microbial-associated molecular patterns (MAMPs). By binding to pattern recognition receptors, including Toll-like receptors, MAMPs can activate immune cells and lead to inflammation. ${ }^{1,2}$ The polarized expression of pattern recognition receptors on the basolateral membrane (or intracellularly) in epithelial cells (ECs) can limit their activation. ${ }^{3}$ However, dendritic cells (DCs) that can intercalate between ECs for direct bacterial uptake ${ }^{4-6}$ could be continuously exposed to MAMP-dependent activation. If not held in check, the development of an exaggerated inflammatory response could lead to chronic inflammation and immune disorders such as inflammatory bowel disease and cancer. Unlike other tissues, lamina propria (LP) derived DCs (LP-DCs) have been shown to be less prone to the development of inflammatory responses. ${ }^{7,8}$ Gutderived $\mathrm{CD}_{103^{+}}$mesenteric lymph node (MLN) DCs (MLNDCs) and LP-DCs have been recently described to actively participate in the de novo generation of $\mathrm{CD} 4{ }^{+} \mathrm{CD} 25^{+} \mathrm{Foxp}^{+}$ regulatory $\mathrm{T}\left(\mathrm{T}_{\text {reg }}\right)$ cells by a retinoic acid (RA)- and TGF- $\beta$ dependent mechanism. ${ }^{9,10}$ This suggests that either a subset of DCs or the local gut microenvironment plays a major role in controlling the activity of DCs, the development of inflammatory reactions, and the induction of tolerance. Interestingly, only the $\mathrm{CD} 103^{+}$population of LP-DCs or MLN-DCs is endowed with tolerogenic properties. As ECs express E-cadherin, ${ }^{11}$ which is the ligand of $\mathrm{CD} 103$, we hypothesized that during the interaction of DCs with ECs, EC-derived factors could participate in driving the tolerogenic mucosal phenotype of gut DCs. Such a mechanism would guarantee that DCs that are in close contact with ECs could be less responsive to MAMP stimulation and might promote the development of adaptive $\mathrm{T}_{\text {reg }}$ cells. Indeed, we show here that ECs induced the expression of CD103 on DCs and conferred upon them a mucosal phenotype through the action of RA and TGF- $\beta$. EC-conditioned DCs (EC-DCs) drove the differentiation of gut-homing $\mathrm{T}_{\text {reg }}$ cells that were protective against experimental colitis. Thus, we have discovered that ECs are not only a barrier between the external and internal world but also play an active role in controlling DC function and intestinal tolerance.

1Department of Experimental Oncology, European Institute of Oncology, Milan, Italy. Correspondence: Maria Rescigno (maria.rescigno@ifom-ieo-campus.it) 


\section{RESULTS}

EC-DCs induce CD4 ${ }^{+} \mathrm{CD}^{2} 5^{+}{ }^{+}{ }$oxp3 ${ }^{+} \mathrm{T}_{\text {reg }}$-cell differentiation in mice

It has been recently shown that DCs of gut origin have the ability to convert naive $\mathrm{T}$ cells into Foxp $3^{+} \mathrm{T}_{\text {reg }}$ cells. ${ }^{9,10}$ However, the mechanism of conferring tolerogenic properties upon gut DCs is still unknown. We reasoned that because of their close interaction with ECs, the ECs could participate in conferring the tolerogenic phenotype upon DCs. To evaluate whether DCs "educated" by ECs were able to promote $\mathrm{T}_{\text {reg }}$-cell differentiation, bone marrow-derived DCs (BMDCs) were incubated for $24 \mathrm{~h}$ with supernatant derived from a murine epithelial cell line (MODE-K). Conditioned DCs were pulsed for $6 \mathrm{~h}$ with ovalbumin (OVA), washed, and co-incubated with naive $\mathrm{CD} 4{ }^{+} \mathrm{CD} 25^{-} \mathrm{T}$ cells from OVA-specific OT-II mice for 5 days. We then analyzed the development of $\mathrm{CD} 4{ }^{+} \mathrm{CD} 25^{+} \mathrm{Foxp}^{+}{ }^{+} \mathrm{T}_{\text {reg }}$ cells by flow cytometry. Conditioning with MODE-K supernatant in the presence of

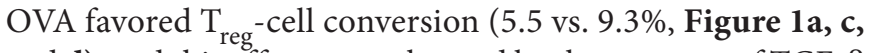
and $\mathbf{d}$ ), and this effect was enhanced by the presence of TGF- $\beta$ during the last 2 days of coculture (13.7 vs. 20.1\%, Figure 1a, c and d). In addition, the capacity of EC-DCs to induce $\mathrm{T}_{\text {reg }}$-cell differentiation was tested using enhanced green fluorescent proteins (eGFP) ${ }^{-} \mathrm{T}$ cells isolated from Foxp3-eGFP reporter mice (Foxp3-GFP). Again, EC-DCs induced a higher rate of conversion of eGFP-Foxp3- into eGFP-Foxp3 ${ }^{+}$T cells than non-conditioned DCs (Supplementary Figure 1a, $\mathbf{c}$ and $\mathbf{d}$ ).

To follow T-cell proliferation in culture, highly purified $\mathrm{CD} 4{ }^{+} \mathrm{CD} 25^{-} \mathrm{T}$ cells were stained with carboxyfluorescein succinimidyl ester (CFSE) before incubation with DCs. At 3 days later, T cells were stained for Foxp3 expression and analyzed for CFSE dilution. EC-DCs induced the development of a higher number of proliferating Foxp $3^{+}$cells, whereas the number of proliferating Foxp3- cells was similar in the two conditions (Figure 1b). The increase of $\mathrm{T}_{\text {reg }}$ cells is likely because of their de novo differentiation rather than because of the expansion of already existing Foxp $3^{+}$cells, as the $\mathrm{CD} 4{ }^{+} \mathrm{CD} 25^{-}$OTII cells used in the experiment expressed negligible levels of Foxp3 (from 0.3 to $0.5 \%$, Figure 1a). The experiments were then repeated using $\mathrm{T}$ cells isolated from DO11.10 SCID mice that have only naive T cells that do not express Foxp $3 .{ }^{9}$ BMDCs were derived from $\mathrm{BALB} / \mathrm{c}$ mice, conditioned with EC supernatants and loaded with OVA as described above. Again, MODE-K-conditioned DCs displayed a greater ability to induce $\mathrm{T}_{\text {reg }}$-cell conversion than do control DCs (Supplementary Figure 1b).

We then compared the ability of EC-DCs with that of nonconditioned BMDCs to influence the development of inflammatory $\mathrm{CD} 4^{+} \mathrm{T}$ cells. T cells incubated with EC-DCs produced lower amounts of interferon- $\gamma$ (IFN- $\gamma$ ) and interleukin (IL)- 17 in response to OVA than those incubated with non-conditioned DCs (Figure 1e). Confirming our previous observations that EC conditioning of human DCs also skewed toward a Th2 phenotype, ${ }^{12}$ we observed an increase in IL-10, IL-13 and IL-5 levels in culture supernatants (Supplementary Figure 2). We were only able to detect low amounts of IL-5, IL-10, and IL-13 released by
T cells, but we have to point out that this was a primary culture; whether these tiny amounts of ILs can exert a biological effect remains to be established, particularly in light of the still relevant Th1 and Th17 cytokines. These results indicate that EC-derived factors "educate" tolerogenic DCs to induce $\mathrm{T}_{\text {reg }}$-cell differentiation and concomitantly limit Th1 and Th17 inflammatory responses.

Next, we compared the suppressor activity of CD25 ${ }^{+} \mathrm{T}_{\text {reg }}$ cells generated by EC-DCs and by non-conditioned DCs with that of $\mathrm{CD} 25^{+}$cells isolated from the mouse spleen. CD25 ${ }^{+} \mathrm{T}$ cells were isolated from conditioned or non-conditioned DC/T-cell cultures, or from the spleen, and incubated in a second proliferating antigen presentation assay using lipopolysaccharide (LPS)matured DCs and CFSE-labeled CD4 ${ }^{+} \mathrm{T}$ cells in the presence of plate-bound $\alpha$-CD3. We found that $\mathrm{CD} 25^{+} \mathrm{T}_{\text {reg }}$ cells generated by EC-DCs were more suppressive than non-conditioned DCgenerated or splenic CD $25^{+} \mathrm{T}_{\text {reg }}$ cells (Figure 1f).

Collectively, our results indicate that ECs can induce tolerogenic DCs and suggest the de novo development of functionally active $\mathrm{T}_{\text {reg }}$ cells. This activity was observed when using conditioned BMDCs from both C57/BL6J and BALB/c mice, suggesting a general rather than a background-restricted phenomenon.

\section{EC-DCs are noninflammatory}

As EC-DCs showed a reduced ability to drive Th1 and Th17 differentiation, we investigated the pattern of cytokines released by EC-DCs. We incubated BMDCs with supernatant from MODE-K cells and stimulated them with LPS $\left(1 \mu \mathrm{g} \mathrm{ml}^{-1}\right)$ for $6 \mathrm{~h}$. We observed that, consistent with their ability to induce $\mathrm{T}_{\text {reg }}$-cell differentiation, EC-DCs produced significantly more IL-10 and IL-2, and less IL-12p70 in comparison with non-conditioned DCs (Figure 2a). In addition, together with the augmented production of cytokines involved in $\mathrm{T}_{\text {reg }}$-cell homeostasis, EC-DCs expressed lower amounts of mRNA coding for inflammatory cytokines involved in the polarization of Th1 (IL-12p35 coded by Il12a) and Th17 (IL-23p19 coded by Il23a) cells (Figure 2b). Hence, EC-DCs display limited production of inflammatory cytokines and drive $\mathrm{T}_{\text {reg }}$-cell differentiation.

\section{Spleen DCs acquire mucosal DC properties and induce $\mathrm{T}_{\text {reg-cell differentiation after "education" by ECs }}$}

LP and MLNs have been reported to be the sites of peripheral $\mathrm{T}_{\text {reg-cell generation, and DCs isolated from these tissues play a }}$ major role in this process. ${ }^{9,10}$ Accordingly, we found that MLNDCs were able to induce the development of $\mathrm{T}_{\text {reg }}$ cells (8.9\%) with considerably higher efficiency compared with spleen DCs (3.2\%) (Figure 3a). However, if splenic DCs were first incubated with MODE-K supernatant, the frequency of $\mathrm{T}_{\text {reg }}$ cells in the cocultures was dramatically increased (9.1\%) (Figure 3a and b). These data indicate that MLN-DCs display a superior ability to drive $\mathrm{T}_{\text {reg }}$-cell differentiation when compared with spleen DCs, a feature that is likely acquired in the periphery after EC conditioning, suggesting that "mucosal" DCs become so only after environmental education. 
a
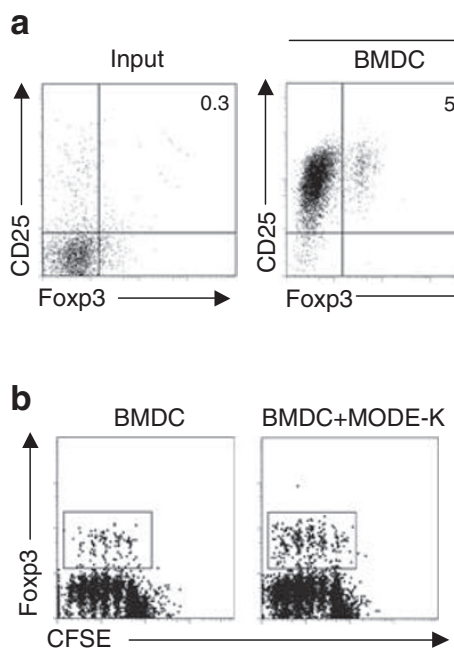

c

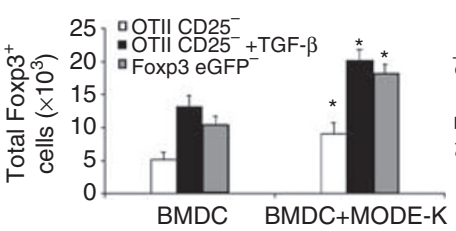

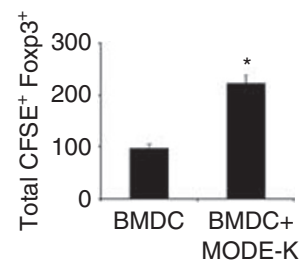

d

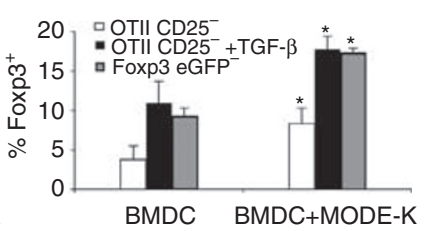

OVA+TGF- $\beta$
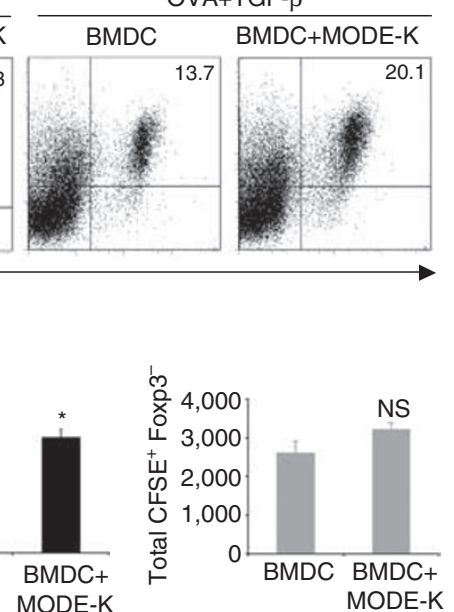

e
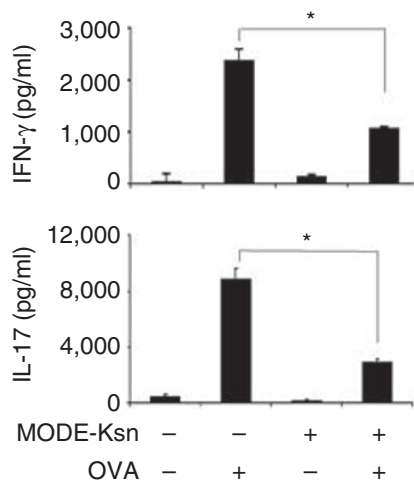

Figure 1 ECs promote tolerogenic DCs able to induce $\mathrm{T}_{\text {reg }}$-cell differentiation. BMDCs $\left(1 \times 10^{4}\right)$ were pretreated with or without MODE-K cell supernatant for $24 \mathrm{~h}$ and pulsed with OVA $\left(250 \mu \mathrm{g} \mathrm{ml}^{-1}\right)$. After washing, cells were incubated together with naive CD4 ${ }^{+} \mathrm{CD} 25^{-}$OT II cells $(\mathbf{a}, \mathbf{c}-\mathbf{e})$ for 5 days (a). Dot plots show CD25 ${ }^{+}$and Foxp $3^{+}$T cells in the CD4 ${ }^{+}$gate. TGF- $\beta\left(3 \mathrm{ng} \mathrm{ml}^{-1}\right)$ was added during the last 2 days of culture. Left panel: input cells. Numbers indicate the percentage of positive cells in the quadrant. Data are representative of five independent experiments. (b) CFSE-labeled CD4 ${ }^{+}$CD25- OTII cells were cultured with OVA-loaded BMDCs as above. After 3 days, the cells were harvested and stained for CD4 and intracellular Foxp3. Dot plots represent Foxp3 vs. CFSE staining. Data are representative of three independent experiments. Graphs show total numbers of $\mathrm{CFSE}^{+} \mathrm{Foxp}^{+}$cells in the gate (left graph) or CFSE ${ }^{+}$Foxp3- cells outside the gate (right graph). (c, d) Pooled data showing absolute numbers (c) or percentage (d) of Foxp3 ${ }^{+}$T cells in the assay in panel a or Supplementary Figure 1a using DCs pulsed with OVA without (open bars) or with TGF- $\beta$ (black bars); or eGFP-Foxp3 ${ }^{+}$T cells (grey bars). (e) IFN- $\gamma$ and IL-17 were measured in culture supernatants by ELISA. Data are representative of three independent experiments. Treatments are reported in the legends below the graphs. (f) CFSE-based suppression assays using CD4 ${ }^{+} \mathrm{CD} 25^{+}$ T cells derived from DC/T-cell cocultures with non-conditioned or MODE-K-conditioned BMDCs. The proliferation of CFSE-labeled responder T cells was analyzed by flow cytometry. One out of two representative experiments is shown. The numbers show percentage of proliferating (left) and nonproliferating (right) cells. (b-e) Error bars, s.d. * $P<0.05$. BMDC, bone marrow-derived DC; CFSC, carboxyfluorescein succinimidyl ester; DC, dendritic cells; IFN- $\gamma$, interferon- $\gamma$; IL-17, interleukin-17; OVA, ovalbumin; $\mathrm{T}_{\text {reg }}$, regulatory $\mathrm{T}$ cells.

The supernatant from intestinal ECs drives the development of $T_{\text {reg }}$ cells

To exclude the possibility that the observed ability of ECs to drive tolerogenic DCs could be due to the use of spent culture medium, which could nonspecifically inhibit DC maturation, we compared the supernatant of MODE-K cells with that of either a mouse mammary tumor epithelial cell line (4T1) or a highly proliferating fibroblast cell line (NIH-3T3) for their ability to drive tolerogenic DCs. As shown in Figure 4a and b, only DCs incubated with MODE-K cell supernatant were able to significantly increase the frequency of $\mathrm{T}_{\text {reg }}$ cells in culture. It has been shown that gut DCs drive the development of $\mathrm{T}_{\text {reg }}$ cells by a mechanism that is dependent on TGF- $\beta$ and RA.9,10 Thus, we evaluated whether TGF- $\beta$ and aldh1a2, an enzyme involved in the conversion of retinal into RA, were expressed by ECs. We also wanted to assess whether differences in the expression of these molecules could explain the diverse abilities of the tested cell lines to induce tolerogenic DCs. We found that only MODEK cells expressed both aldh1a2 and TGF- $\beta$, whereas 4 T1 and
NIH-3T3 cells expressed only TGF- $\beta$ (Figure 4c). We then purified primary ECs from the small intestine of mice and collected their supernatant after $24 \mathrm{~h}$ of culture to rule out the possibility that the ability of MODE-K cells to induce tolerogenic DCs was an artifact of this cell line (Supplementary Figure 3a and b). BMDCs incubated with RA were used as a positive control for the experiment. Similar to MODE-K cells, the supernatant from primary ECs of the small intestine strongly favored the development of $\mathrm{T}_{\text {reg }}$-polarizing DCs (Supplementary Figure $3 \mathbf{a}$ and $\mathbf{b}$ ).

\section{EC-derived TGF- $\beta$ and RA induce tolerogenic DCs}

As we have shown that MODE-K cells expressed TGF- $\beta$ and an enzyme involved in RA synthesis, we analyzed whether TGF$\beta$ and RA played any role in driving tolerogenic DCs, which would be able to induce $\mathrm{T}_{\text {reg }}$-cell development. Thus, BMDCs were incubated with MODE-K supernatant, with or without antibody neutralization of TGF- $\beta$, before T-cell activation. Indeed, neutralization of TGF- $\beta$ in the MODE-K supernatant 
a
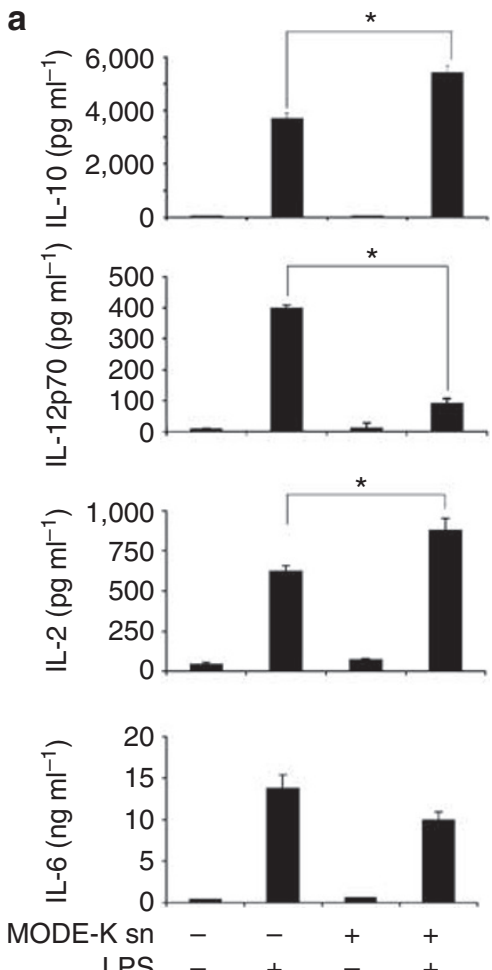

b
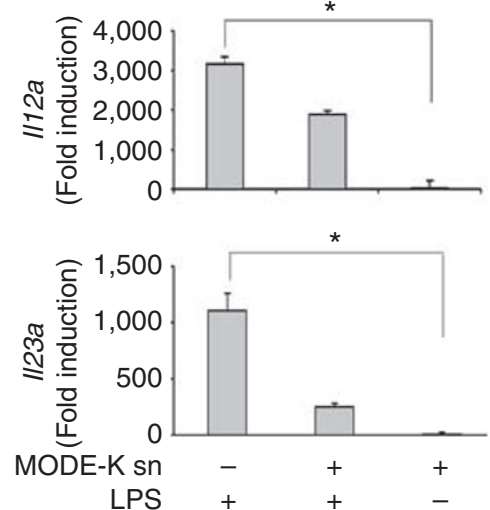

Figure 2 Epithelial cell-conditioned BMDCs are noninflammatory. BMDCs were pretreated with or without MODE-K cell supernatant for $24 \mathrm{~h}$ and stimulated with or without LPS $\left(1 \mu \mathrm{g} \mathrm{ml}^{-1}\right)$ for $6 \mathrm{~h}$. (a) IL-10, IL-12p70, IL-2, and IL-6 released in the culture supernatants were measured by ELISA after 24h. (b) II23a (IL-23p19) and I/12a (IL-12p35) expressions were analyzed by quantitative RT-PCR and normalized to Tbp mRNA. Data represent fold induction over immature BMDCs. Treatments are reported in the legends below the graphs. The difference in cytokine production or RNA expression between MODE-K conditioned and non-conditioned BMDCs was statistically significant $\left({ }^{\star} P<0.05\right)$. Data are representative of three independent experiments. BMDC, bone marrow-derived DC; IL-17, interleukin-17; LPS, lipopolysaccharide; RT-PCR, reverse transcriptase-PCR.

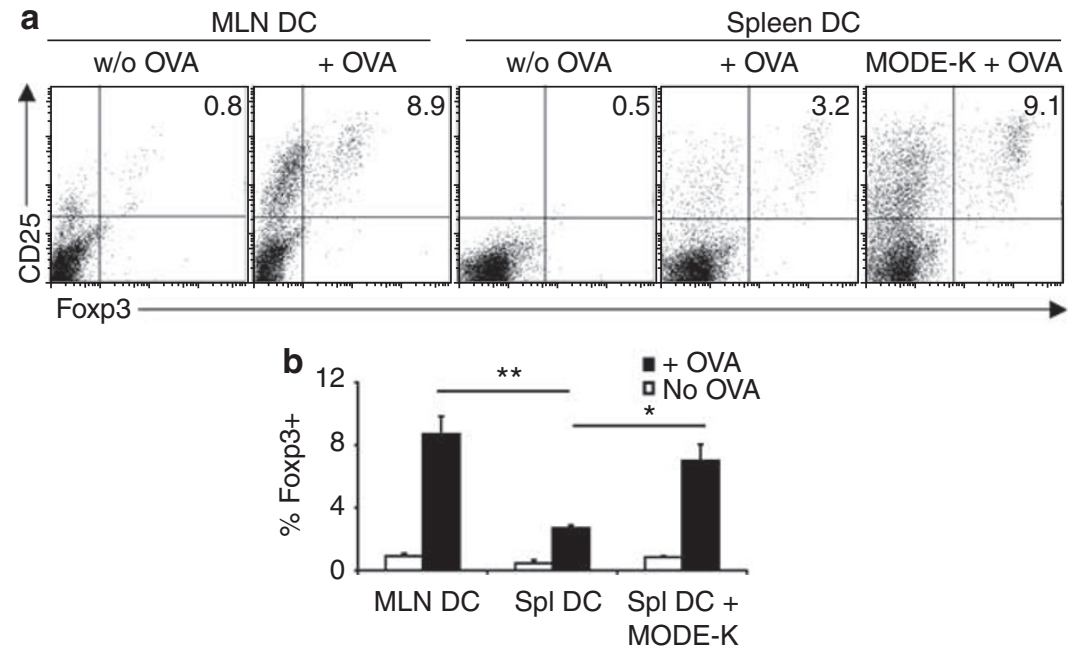

Figure 3 ECs imprint spleen DCs with a mucosal phenotype. (a) CD11 $\mathrm{c}^{+} \mathrm{DC}$ s were isolated from MLNs and the spleens of C57/BL6J mice. MLN-DCs and spleen DCs (with or without MODE-K conditioning) were pulsed with OVA $\left(250 \mu \mathrm{g} \mathrm{ml}^{-1}\right)$ for $6 \mathrm{~h}$, washed, and incubated with naive CD4 ${ }^{+} \mathrm{CD} 25^{-}$ OTII cells for 5 days. Development of $C D 4^{+} \mathrm{CD} 25^{+}$Foxp3 ${ }^{+} T_{\text {reg }}$ cells was analyzed by FACS. Dot plots representative of two independent experiments are shown. (b) Graph represents pooled data from the experiments described in (a). DC, dendritic cells; EC, epithelial cells; MLN, mesenteric lymph node; OVA, ovalbumin ${ }^{*} P<0.05 ;{ }^{* *} P<0.01$.

lead to a strong reduction in the frequency of $\mathrm{T}_{\text {reg }}$ cells in ECDC/T-cell cultures (23.0\% vs. $11.6 \%$ ) (Figure 5a and $\mathbf{b}$ ) and correlated with increased IFN- $\gamma$ production (Figure 5c). This was not due to unspecific effects of the neutralizing antibody because an isotype control had no effect on $\mathrm{T}_{\text {reg }}$-cell development (Figure 5a and $\mathbf{b}$ ). We then tested whether EC-derived RA was also required for the differentiation of tolerogenic DCs. DCs were incubated with an RA receptor inhibitor (LE540) for $1 \mathrm{~h}$ 


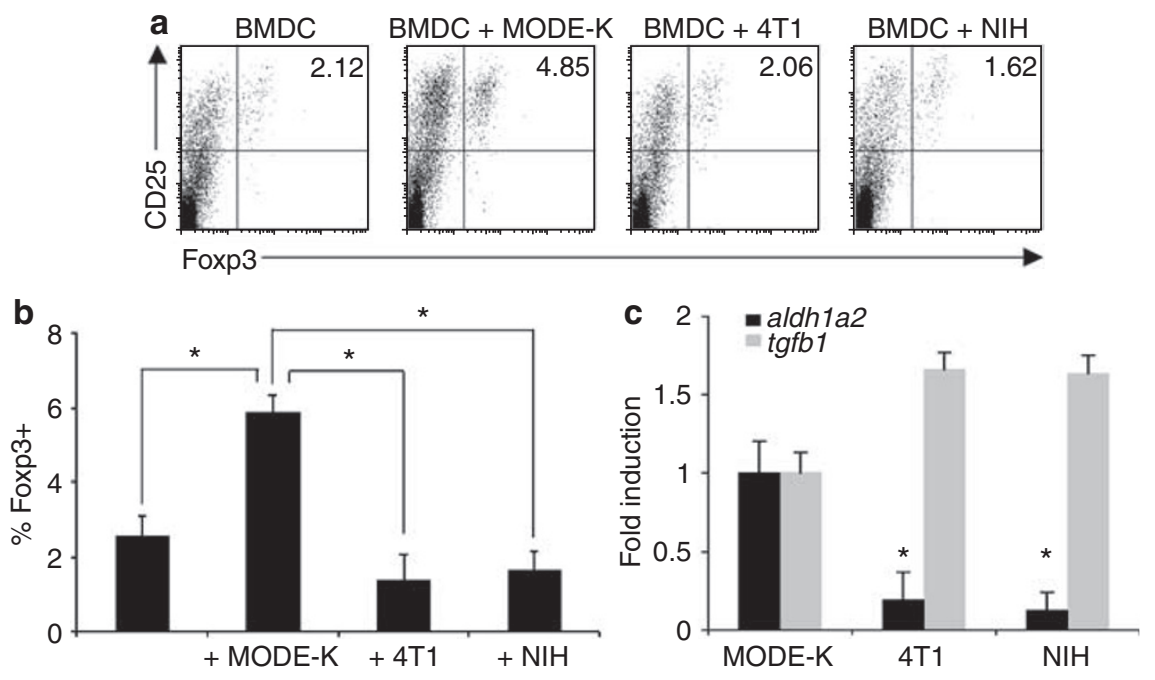

Figure 4 IEC, but not supernatants from fibroblast or mammary ECs, promote tolerogenic DCs. BMDCs were either incubated with supernatants derived from MODE-K cells, mammary tumor ECs (4T1), or a fibroblast cell line (NIH-3T3). At 24 h later, cells were collected, pulsed with OVA, and cocultured with naïve OTII cells, as described in Figure 1. (a) Dot plots show CD25 ${ }^{+}$Foxp3 ${ }^{+} \mathrm{T}$ cells. Numbers indicate the percentage of positive cells in the quadrant. (b) The graph shows pooled data from the experiments described in panel a. (c). Fold induction of aldh1a2 and tgfb1 in cell lines normalized to Tbp mRNA. Error bars, s.d. ${ }^{*} P<0.05$. Data are representative of two independent experiments. BMDC, bone marrow-derived DC; DC, dendritic cells; EC, epithelial cells; OVA, ovalbumin.

before conditioning. At $24 \mathrm{~h}$ later, DCs were washed and incubated with naive OTII T cells, as above. We found that inhibition of RA signaling to DCs affected the induction of $\mathrm{T}_{\text {reg }}$ cells (Figure 5d and e) and restored the development of Th17 responses (Figure 5f). However, we could not detect any synergistic effect in the inhibition of $\mathrm{T}_{\text {reg }}$-cell differentiation by blocking both TGF- $\beta$ and RA (data not shown). RA is likely derived from ECs in our experimental setting, as we found no increase in aldh1a2 expression in EC-DCs as compared with DCs alone, whereas intestinal ECs displayed a nearly three times higher expression of the enzyme than DCs (Figure 5g). On the other hand, aldh1a2 was highly expressed in colon tissue and MLN than in the spleen (Figure 5g). In particular, the $\mathrm{CD}_{103}{ }^{+} \mathrm{DC}$ subset isolated from MLN showed the highest expression of aldh1a2 (Figure 5g), suggesting that DC-derived RA may also participate in $\mathrm{T}_{\text {reg }}$ conversion at mucosal sites in vivo.

Similar to what we already described in humans, ${ }^{12}$ we found that MODE-K cells and primary murine ECs constitutively expressed TSLP (Supplementary Figure 4). Thus, we compared the ability of DCs isolated from MLN- or BM-DCs from $\mathrm{TSLPR}^{-1-}$ mice to induce $\mathrm{T}_{\text {reg }}$-cell differentiation. The functional receptor for TSLP comprises two chains: IL7R $\alpha$ chain, which is shared with IL-7 receptor, and a TSLP receptor chain (TSLPR). ${ }^{13}$ Our results show that both TSLPR ${ }^{-1-}$ and WT DCs (Figure 6a and $\mathbf{b}$ ) had a similar ability to convert naive $\mathrm{T}$ cells into $\mathrm{T}_{\text {reg }}$ cells, both before and after EC conditioning. All together, these results suggest that EC-derived TGF- $\beta$ and RA are needed for the promotion of the tolerogenic phenotype of DCs in mice, but TSLP could be dispensable.

\section{EC contact drives CD103 expression on DCs that become tolerogenic}

As DCs interact closely with ECs in the gut, we evaluated whether the proximity to ECs had differentially effected DC conditioning. Hence, we opted for the mouse CMT93 epithelial cell line that, unlike MODE-K cells, is able to form EC monolayers. CMT93 cells were grown on a transwell and murine BMDCs were added to the basolateral side of the EC monolayer. We measured the ability of DCs conditioned by CMT93 supernatant or direct CMT93 contact to drive the development of $\mathrm{T}_{\text {reg }}$ cells. We found that in agreement with MODE-K cells, CMT93 supernatants were capable of driving the differentiation of tolerogenic DCs, but EC contact did not confer further differentiation (Figure $\mathbf{7 b}$ and $\mathbf{e}$ ). As it has been shown that murine intestinal $\mathrm{CD} 103^{+} \mathrm{DCs}$ are able to convert naive T cells into Foxp $3^{+} \mathrm{T}_{\text {reg }}$ cells ${ }^{9}$ and are required for T-cell-mediated prevention of experimental colitis, ${ }^{14}$ we asked whether EC contact could induce CD103 expression on BMDCs. Interestingly, CD103 was strongly upregulated on BMDCs after $24 \mathrm{~h}$ of direct contact with ECs (Figure 7a and $\mathbf{d}$ ). DCs incubated with EC supernatants were also able to upregulate CD103, but to a lower extent (Figure 7a and d). When $\alpha$-TGF- $\beta$ ( 10 or $50 \mu \mathrm{g} \mathrm{ml}^{-1}$ ) or LE540 (1 or $10 \mathrm{nM}$ ) were added to the EC-DC cocultures, we could not inhibit CD103 upregulation (data not shown). We then analyzed whether $\mathrm{CD} 103^{+}$and $\mathrm{CD} 103^{-}$cells obtained after contact with ECs had different abilities to drive $\mathrm{T}_{\text {reg }}$ cells. As shown in Figure 7c-e, FACS (fluorescence-activated cell sorting)-sorted $\mathrm{CD}_{103}{ }^{+}$cells showed a more than fourfold greater ability to drive $\mathrm{T}_{\text {reg }}$-cell development than did CD103- DCs. This correlated with the ability of CD103+ but not CD103- DCs to induce the expression of $\alpha 4 \beta 7$, an integrin involved in the homing of lymphocytes to the gut, on Foxp $3^{+}$cells and with a reduced production of IFN- $\gamma$ and IL-17 (Figure 7f and $\mathbf{g}$ ). Interestingly, the contact with ECs induced the expression of aldh1a2 in DCs to a similar level as RA (Figure 7h). Together, these results suggest that EC contact by DCs promotes a full CD $103^{+} \mathrm{DC}$ mucosal tolerogenic phenotype. 
a

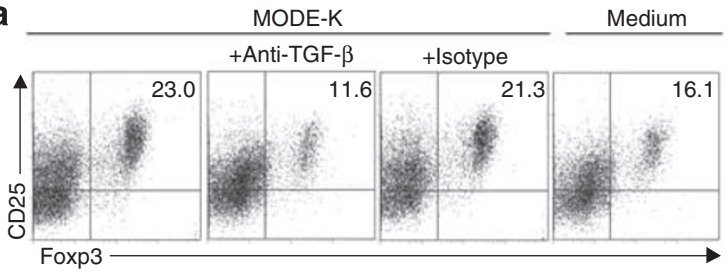

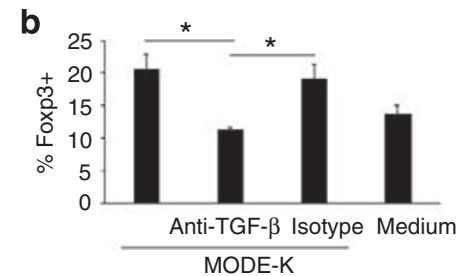
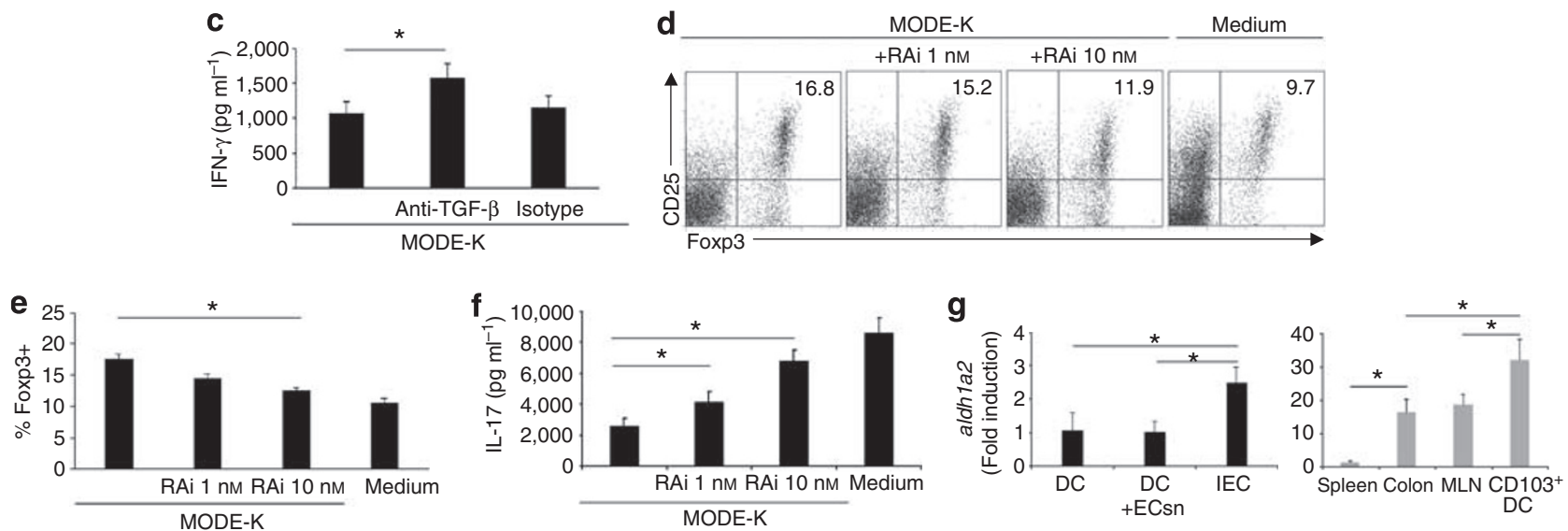

Figure 5 ECs induce tolerogenic DCs by a TGF- $\beta$ and RA-dependent mechanism. MODE-K supernatants were pre-incubated for $2 \mathrm{~h}$ at $4{ }^{\circ} \mathrm{C}$ with (a-c) $50 \mathrm{\mu g} \mathrm{ml}^{-1}$ anti-TGF- $\beta$ or an isotype control. BMDCs were pre-incubated (d-f) either with or without RAi (LE540) for $1 \mathrm{~h}$ at $37^{\circ} \mathrm{C}$ were then conditioned for $24 \mathrm{~h}$ with neutralized or control supernatants, pulsed with OVA, and cocultured with naive OTII cells as described in Figure 1. (a, d) Dot plots show $\mathrm{CD}_{2} 5^{+}$and Foxp3 ${ }^{+} \mathrm{T}$ cells in the $\mathrm{CD} 4^{+}$gate. Numbers show the percentage of cells in the gate. Graphs (b) and (e) show pooled data from the experiments described in panel a and d, respectively. (c) IFN- $\gamma$ production in the cocultures from panel a was assessed by ELISA. (f) IL-17 production in cocultures from panel d was measured by ELISA. (g) aldh1a2 expression level in BMDCs (DC), BMDC+MODE-K supernatant (DC+ ECsn), primary IEC, spleen, colon, MLN, and FACS-sorted CD103+ DC isolated from MLNs (CD103+ DC). aldh1a2 mRNA expression was analyzed by quantitative RT-PCR, normalized to rp/32 mRNA and displayed as fold induction vs. untreated DCs (left) or spleen (right). (b, c, e-g) Error bars, s.d. ${ }^{*} P<0.05$. Data are representative of three independent experiments $(\mathbf{a}-\mathbf{c})$ or two independent experiments $(\mathbf{d}-\mathbf{g})$. BMDC, bone marrow-derived DC; DC, dendritic cells; EC, epithelial cells; IFN- $\gamma$, interferon- $\gamma$; IL-17, interleukin-17; LPS, lipopolysaccharide; MLN, mesenteric lymph node; OVA, ovalbumin; RT-PCR, reverse transcriptase-PCR; TGF- $\beta$, transforming growth factor- $\beta$.

\section{EC-DC-induced $\mathrm{T}_{\text {reg }}$ cells are protective in vivo against experimental colitis}

We showed that EC-DCs acquired the ability to drive $\mathrm{T}_{\text {reg }}$-cell differentiation. Thus, we asked whether these newly generated $\mathrm{T}_{\text {reg }}$ cells might have a protective function in vivo in the gut. $\mathrm{T}_{\text {reg }}$ cell-enriched populations were generated using either BMDCs conditioned or unconditioned for $24 \mathrm{~h}$ with MODE-K supernatants after culture with $\mathrm{CD} 4{ }^{+} \mathrm{CD} 25^{-} \mathrm{T}$ cells from the same mice. After 5 days of coculture, the frequency of CD $4{ }^{+} \mathrm{CD} 25^{+}$Foxp $3^{+}$ $\mathrm{T}_{\text {reg }}$ cells in the two conditions was analyzed by FACS (Figure 8a). As we found that EC-DCs induce twice as many $\mathrm{T}_{\text {reg }}$ cells, we wondered whether their frequency could be functionally significant and have an impact on the development of colitis. Thus we injected intravenous $1 \times 10^{6}$ total T cells (Figure 8) or purified CD25 ${ }^{+}$T cells (Supplementary Figure 5) - or PBS (phosphate buffered saline) as a control-into C57/BL6J mice $8 \mathrm{~h}$ before colitis induction with $2 \%(\mathrm{w} / \mathrm{v})$ dextran sulfate sodium (DSS). The onset of DSS colitis was characterized by weight loss in all groups. Interestingly, mice adoptively transferred with total or purified CD25 ${ }^{+} \mathrm{T}$ cells generated using EC-DCs experienced reduced weight loss and a faster recovery as compared with the other two groups (Figure $\mathbf{8 b}$ and Supplementary Figure 5). Twelve days from the beginning of DSS administration, mice receiving PBS or T cells generated with non-conditioned DCs still displayed signs of robust colitis, including swollen colons, contracted ceca, and watery stools (Figure 8c). Histopathological analysis confirmed that mice with gross alterations in intestinal appearance also displayed altered histology, including focal crypt epithelial destruction and extensive areas of epithelial hyperplasia associated with mononuclear infiltrates (Figure 8d). Consistent with the histology, mice receiving PBS or T cells generated with non-conditioned DCs displayed significantly increased amounts of IFN- $\gamma$ and TNF- $\alpha$ in the colons, compared with those receiving EC-DC-derived T cells (Figure $\mathbf{8 e}$ ). In all groups of mice, we could not detect any significant difference in IL-6 production (data not shown). These data suggest that EC-DCs are able to effectively induce the generation of colitis-protective $\mathrm{T}_{\text {reg }}$ cells.

\section{DISCUSSION}

It is becoming increasingly clear that immune cells isolated from mucosal tissues exhibit very peculiar phenotypes. ${ }^{8}$ Macrophages, for instance, display bactericidal activity without inducing inflammation, ${ }^{15}$ drive the development of $\mathrm{T}_{\text {reg }}$ cells, and control DC function. ${ }^{16}$ DCs isolated from either Peyer's patches or the LP are also noninflammatory, $8,17,12,18,19,35$ and a subtype of MLN-DCs expressing CD103 is involved in T-cell-mediated regulation of experimental colitis. ${ }^{14} \mathrm{CD} 103^{+} \mathrm{DCs}$ impart guthoming properties to $\mathrm{T}$ cells ${ }^{20}$ and drive the development of $\mathrm{T}_{\text {reg }}$ cells by a RA- and TGF- $\beta$-dependent mechanism. ${ }^{9,10}$ 
a
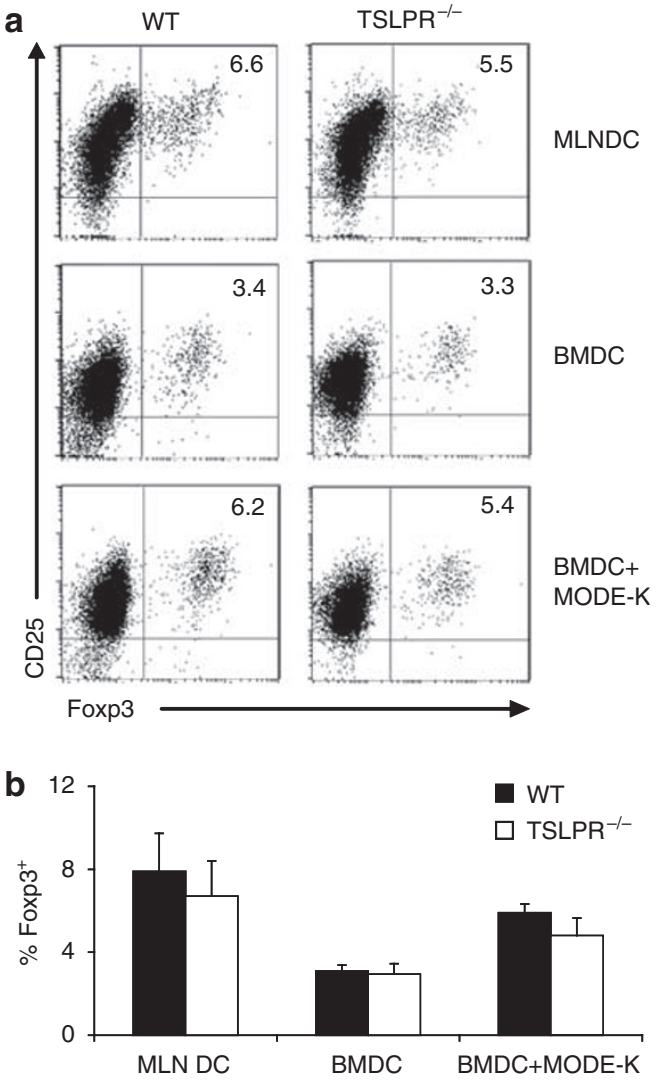

Figure 6 TSLP is not involved in the induction of tolerogenic DCs in mice. (a) $\mathrm{CD} 11 \mathrm{c}^{+} \mathrm{DCs}$ isolated from MLNs or BMDCs (conditioned or unconditioned with MODE-K supernatants) from wild-type C57/BL6J and TSLPR ${ }^{-/-}$mice were pulsed with OVA $\left(250 \mu \mathrm{g} \mathrm{ml}^{-1}\right)$, washed, and incubated together with naive CD4 ${ }^{+}$CD25- OT II cells for 5 days. The number of $T_{\text {reg }}$ cells in the cultures was evaluated by FACS. Dot plots represent $\mathrm{CD} 25^{+} \mathrm{Foxp}^{+} \mathrm{T}$ cells inside the $\mathrm{CD} 4^{+}$gate. Numbers indicate the percentage of positive cells in the quadrant. Data are representative of three experiments. (b) Graph shows pooled data from the experiments described in panel a. BMDC, bone marrow-derived DC; DC, dendritic cells; MLN, mesenteric lymph node; OVA, ovalbumin; $T_{\text {reg }}$, regulatory $T$ cells; TSLP, thymic stromal lymphopoietin.

All this evidence strongly supports the notion that gut DCs confer "mucosal" properties to effector immune cells, but still very little is known on what drives the "mucosal" phenotype of the DCs. Our results emphasize the role of the microenvironment, and in particular of intestinal ECs, in the control of DC function by driving the development of "tolerogenic mucosal" DCs. EC-DCs released higher amounts of IL-2 and IL-10 in response to LPS when compared with non-conditioned DCs, and drove the de novo generation of $\mathrm{CD} 4{ }^{+} \mathrm{CD} 25^{+} \mathrm{Foxp} 3^{+} \mathrm{T}_{\text {reg }}$ cells, which were suppressive. In agreement with an involvement of the mucosal environment, spleen DCs incubated with EC supernatant displayed increased ability to generate de novo $\mathrm{T}_{\text {reg }}$ cells, which was similar to that of MLN-DCs. The ability of DCs to drive $\mathrm{T}_{\text {reg }}$ cells correlated with a decreased production of IL-12 and IL-23, and a reduced ability to drive Th1 and Th17 development. Furthermore, DCs in close proximity with ECs upregulated the expression of CD103, a marker that characterizes MLN tolerogenic DCs coming from mucosal sites. ${ }^{20}$ When
FACS-sorted, primarily the $\mathrm{CD} 103^{+} \mathrm{EC}-\mathrm{DC}$ displayed tolerogenic properties and upregulated $\alpha 4 \beta 7$, confirming that CD103 is a marker of gut-derived tolerogenic DCs and that the interaction with ECs confers full mucosal properties to DCs. Despite an increase in $\mathrm{CD}_{103}{ }^{+}$cells and the induction of aldh $1 \mathrm{a} 2 \mathrm{after}$ EC contact, the number of converted Foxp $3^{+} \mathrm{T}$ cells was similar to that obtained after simple supernatant conditioning, suggesting that the contact-dependent interaction might also confer different properties. It is possible that $\mathrm{CD} 103^{+} \mathrm{DCs}$ might play a role in IgA class switching, as RA has been shown to play a fundamental role in driving IgA development ${ }^{21}$ and that mouse LP-DCs express higher levels of aldh1a2 and are involved in IgA class switching. ${ }^{22-24}$ Our data would support the notion that MLN CD103 ${ }^{+}$DCs could migrate from the LP, where they had received signals from the local environment, resulting in an inhibited inflammatory potential, the upregulation of CD103 after contact with Ecs, and the ability to induce $\mathrm{T}_{\text {reg }}$ cells. The finding that aldh1a2 is upregulated after EC contact and is expressed by MLN $\mathrm{CD}_{103}{ }^{+}$cells supports this hypothesis. Thus, we describe that ECs are conductors of DC function and disrupting this balance could result in inflammatory disorders.

What are the factors involved in generating tolerogenic DCs? We found that EC-derived TGF- $\beta$ and RA are necessary to drive the tolerogenic phenotype of DCs, because neutralization of either one was sufficient to affect the differentiation of $\mathrm{T}_{\text {reg }}$ cells. However, TGF- $\beta$ alone is not sufficient to drive tolerogenic DCs as cell lines such as NIH-3T3 or 4T1 that are producing it even at higher levels than MODE-K cells still were unable to drive tolerogenic DCs at the same frequency. This is likely because of the reduced expression of the RA-converting enzyme 5 by $4 \mathrm{~T} 1$ and NIH-3T3 cells, as RA signaling synergizes with TGF- $\beta$ to favor $\mathrm{T}_{\text {reg }}$-cell conversion. ${ }^{9,10}$ We could detect an upregulation of aldh1a2 in DCs after EC contact, but not after incubation with EC supernatant, suggesting that EC-derived $\mathrm{RA}$ is sufficient for the polarization of $\mathrm{T}_{\text {reg }}$-promoting DCs. In agreement with recently published reports, ${ }^{25,26}$ EC-derived RA was also involved in inhibiting Th17 responses as suppression of RA signaling restored IL-17 production in EC-DC/T-cell cocultures. It is likely that in proximity to ECs, RA is present at higher concentrations and hence inhibits Th17 induction. By contrast at a greater distance from ECs, the RA concentration might decrease and it has been shown that low levels of RA favor Th17 induction. ${ }^{22}$ In addition, a subset of LP-DCs that expresses $\mathrm{CD} 70$ (CD11 $\left.\mathrm{c}^{\text {low }} \mathrm{CD} 70^{\text {high }}\right)$ and a unique series of ATP receptors was shown to respond to bacteria-derived ATP and to favor the development of Th17 cells. ${ }^{27,28}$ This suggests that CD103+ and $\mathrm{CD} 70^{+} \mathrm{DC}$ subsets may respond to the local microenvironmet differently according to their surface receptors and exert diverse activities. Finally, TSLP, which is produced by Intestinal epithelial cells, was not involved in the induction of tolerogenic DCs in mice, as DCs isolated from MLNs of TSLPR ${ }^{-1-}$ mice displayed a phenotype similar to WT MLN-DCs. It is likely that EC-derived TSLP primarily plays a role in Th1/Th2 control in the mouse system, as described previously by Zaph et al. ${ }^{29}$

$\mathrm{T}_{\text {reg }}$ cells play a major role in the immune homeostasis of the gut: adoptive transfer of antigen-experienced T cells, includ- 

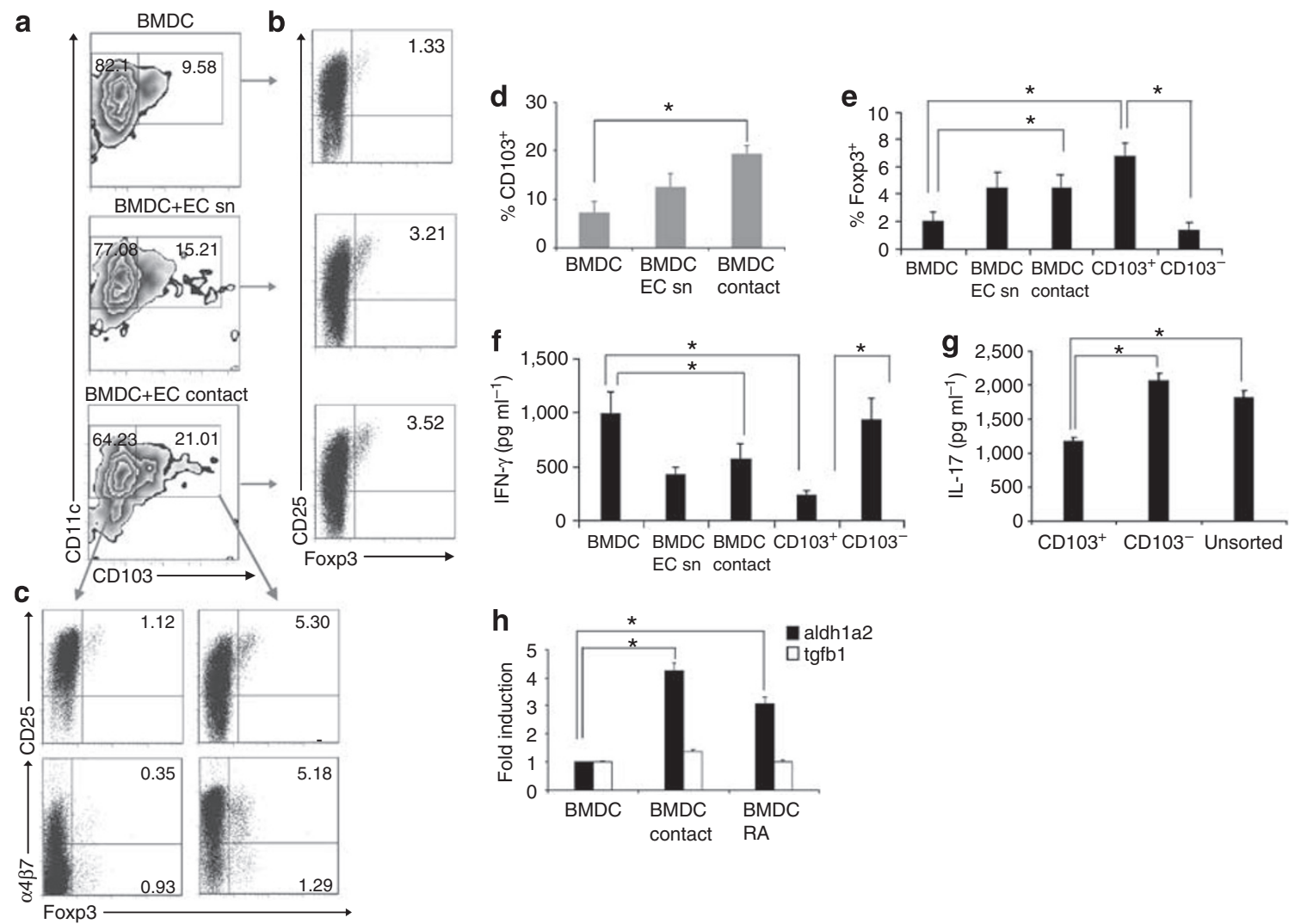

Figure 7 Epithelial cells drive the development of tolerogenic CD103 ${ }^{+}$DCs. (a) Density plots show CD11c ${ }^{+}$CD103 ${ }^{+}$cells. Epithelial cells (ECs, CMT93) were grown on a transwell. BMDCs were incubated for $24 \mathrm{~h}$ on the basolateral side of the EC monolayer (BMDC EC contact; lower panel). For comparison, BMDCs were either pretreated (BMDC EC sn; middle panel) or untreated (BMDC, upper panel) with CMT93 supernatants. DCs were stained for CD11C and CD103, and analyzed by FACS. Numbers represent the percentage of cells in the gate. (b) Dot plots display CD25 ${ }^{+}$and Foxp $3^{+}$cells arisen from cocultures with BMDCs treated as above. (c) $\mathrm{CD}_{103^{+}}$and $\mathrm{CD}_{103^{-}}$cells were FACS-sorted from EC contact-conditioned DCs (arrows) and used in T-cell cocultures. Dot plots of CD25 ${ }^{+}$Foxp3 ${ }^{+}$(upper dot plots) and á4 $37^{+}$Foxp3 ${ }^{+}$(lower dot plots) cells are shown. (d) Pooled data from two experiments as in panel a showing the percentage of generated CD103 ${ }^{+}$DCs. (e) Pooled data from two experiments as in panels $b$ and c showing percentage of Foxp3 $3^{+}$T cells. (f) IFN- $\gamma$ and $(\mathbf{g})$ IL-17 production in coculture supernatants was measured by ELISA. (h) Fold induction of aldh1a2 and tgfb1 in DCs after EC contact or RA treatment normalized to Tbp mRNA. (d-h) ${ }^{\star} P<0.05$. Error bars, s.d. BMDC, bone marrow-derived DC; DC, dendritic cells; EC, epithelial cells; IFN- $\gamma$, interferon- $\gamma$; IL, interleukin; RA, retinoic acid.

ing $\mathrm{T}_{\text {reg }}$ cells, can protect against experimental colitis. ${ }^{30,31}$ MLN CD $103^{+}$DCs are involved in T-cell-mediated regulation of experimental colitis ${ }^{14}$ presumably by the generation of $\mathrm{T}_{\text {reg }}$ cells. However, the functionality of mucosally derived adaptive $\mathrm{T}_{\text {reg }}$ cells has not been tested previously. As EC-DCs display properties very similar to mucosal tolerogenic DCs, we used them to generate $\mathrm{T}_{\text {reg }}$ cells ex vivo to study their function during experimental colitis. We show that ex vivo EC-DCs generated a greater number of $\mathrm{T}_{\text {reg }}$ cells, which were effective suppressors of T-cell proliferation in vitro and extremely potent in protecting against colitis in vivo. $\mathrm{T}_{\text {reg }}$ cells were found to be generated by EC-DCs twofold above the rate observed using non-conditioned DCs, and although the physiological consequence of this difference cannot be predicted, still the observed effect was clear and consistently striking. This could be because of an increased suppressor activity (as shown in Figure 1f), a higher frequency, or a greater gut-homing ability of EC-DC-generated $\mathrm{T}_{\text {reg }}$ cells. Indeed, we describe that EC-CD103 ${ }^{+}$DCs upregulated the expression of the gut-homing marker, $\alpha 4 \beta 7$, on $\mathrm{T}_{\text {reg }}$ cells, thus suggesting that not only can EC-DCs drive $\mathrm{T}_{\text {reg }}$-cell development but they can also imprint them with gut-homing properties, similar to gut DCs. ${ }^{26}$

In conclusion, we describe that ECs play a major role in controlling DC function by conferring upon them a tolerogenic "mucosal" phenotype. EC-DCs can induce the development of gut-homing $\mathrm{T}_{\text {reg }}$ cells with potent suppressor activity that protect against experimental colitis. This could open new avenues for possible therapeutic intervention. For instance, in a hypothetical treatment of inflammatory bowel disease, the use of gut-derived DCs for the generation of $\mathrm{T}_{\text {reg }}$ cells is not feasible because of their paucity and difficulty of isolation. Thus, we propose a new therapeutic tool of imprinting ex vivo a "mucosal" tolerogenic phenotype to DCs for the development of gut-homing $\mathrm{T}_{\text {reg }}$ cells. Our approach could offer a valid alternative to standard anti-inflammatory therapies that could revolutionize the treatment of inflammatory bowel disease.

\section{METHODS}

\section{Mice}

Female C57BL6J mice or BALB/c mice (6-7 weeks old) were purchased from Charles River, Milan, Italy. DO11.10 BALB/c and DO11.10 SCID 
a

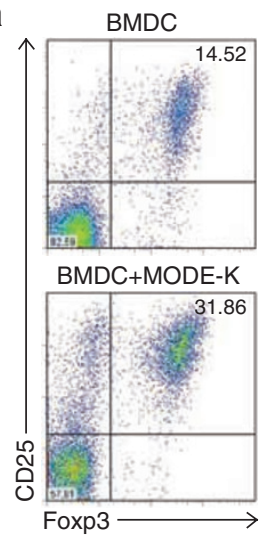

b

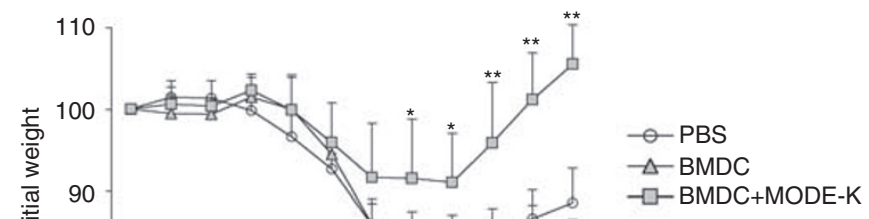

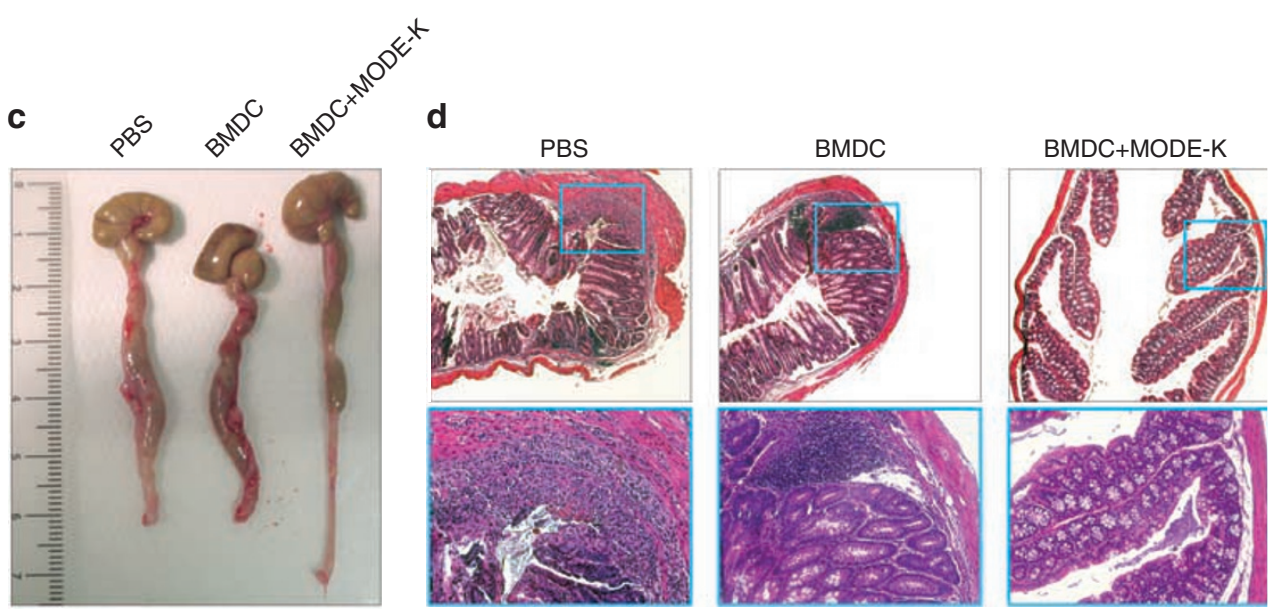
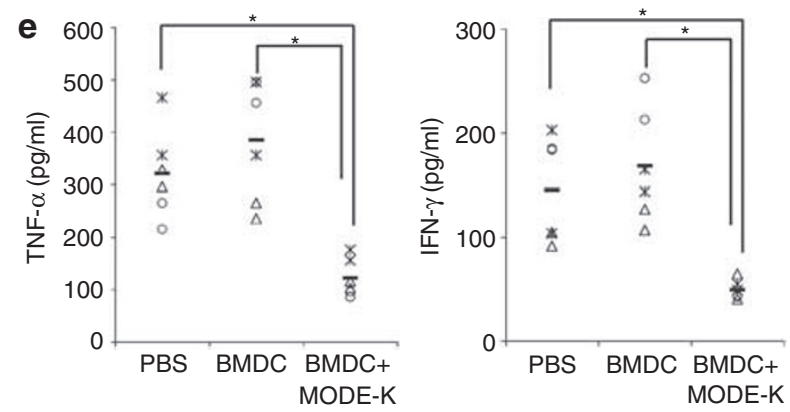

Figure 8 EC-DC generated $T_{\text {reg }}$ cells are strongly protective and ameliorate inflammation in DSS colitis. BMDCs were incubated with or without MODE-K supernatants for $24 \mathrm{~h}$, cocultured with naive CD4 ${ }^{+} \mathrm{CD} 25^{-}$T cells for 5 days and TGF- $\beta\left(3 \mathrm{ng} \mathrm{ml} \mathrm{m}^{-1}\right)$ was added during the last 3 days of culture. (a) The number of $\mathrm{T}_{\text {reg }}$ cells in the cocultures was evaluated by FACS. Dot plots show CD25+Foxp3 ${ }^{+} \mathrm{T}^{+}$cells in the CD4 ${ }^{+}$gate. Numbers show the percentage of cells in the quadrant. (b) Total T cells $\left(1 \times 10^{6}\right)$ from the cocultures of naive T cells with non-conditioned BMDC (BMDC) or with MODE-K-conditioned BMDC (BMDC + MODE-K) were injected intravenously $8 \mathrm{~h}$ before induction of DSS colitis. The control group was injected only with PBS. Data represent mean body weight of the mice as a percentage of the initial weight on day $0(n=4)$. ${ }^{*} P<0.05$; ${ }^{\star \star} P<0.02$, for the BMDC group against the BMDC+MODE-K group. (c) Gross appearance of cecum and colon 12 days after colitis induction. (d) Hematoxylin and eosin staining of mouse colonic sections 12 days after colitis induction. Original magnification, $\times 10$ (upper panel), $\times 20$ (lower panel). (e) Colon specimens ( $1 \mathrm{~cm}^{2}$ ) were collected on day 12 and were incubated in triplicate for $24 \mathrm{~h}$ in RPMI. Cytokine production in the supernatants was measured by ELISA. Data are representative of two experiments. Error bars, s.d. ${ }^{*} P<0.05$. BMDC, bone marrow-derived DC; DSS, dextran sulfate sodium; EC-DC, EC-conditioned DCs; FACS, fluorescence-activated cell sorting; PBS, phosphate buffered saline; $\mathrm{T}_{\text {reg}}$, regulatory $\mathrm{T}$ cells.

TCR transgenic mice were maintained in microisolator cages in our specific pathogen-free animal facility. TSLPR ${ }^{-1-}$ mice on C57/BL6J background were kindly provided by Dr Warren J Leonard ${ }^{32}$ and OTII mice were purchased from Charles River. Foxp3-eGFP reporter mice were provided by M Oukka (Brigham and Women's Hospital, Cambridge, MA) ${ }^{33}$ and were kindly provided by Dr Yasmine Belkaid (NIH). Animals were bred and maintained in our conventional animal facility. All experiments were carried out in accordance with the guidelines established in the Principles of Laboratory Animal Care (directive 86/609/EEC).

\section{DC cultures and EC isolation}

BMDCs were generated from the bone marrows of C57/BL6J, BALB/c, or TSLPR ${ }^{-1}$ - mice, cultured in Iscove's modified Dulbecco's medium supplemented with $10 \%$ fetal bovine serum, $2 \mathrm{mmoll}^{-1}$ glutamine, $100 \mathrm{IU} \mathrm{ml}^{-1}$ penicillin, $100 \mathrm{\mu g} \mathrm{ml}^{-1}$ streptomycin, $50 \mu \mathrm{moll}^{-1}$ 
2-mercaptoethanol, and 30\% supernatant from granulocytemacrophage colony-stimulating factor-producing NIH-3T3 cells. Spleen and MLN-DCs were isolated by gentle collagenase treatment $\left(1 \mathrm{mg} \mathrm{ml}^{-1}\right)$ and purification of CD11 $\mathrm{c}^{+}$cells was carried out by FACS (MLN-DC purity $>97 \%$ ) or MACS (spleen DC, Miltenyi, Caldenara di Reno, BO, Italy). $\mathrm{CD}_{103}{ }^{+}$and $\mathrm{CD} 103^{-}$DCs were sorted by flow cytometry on FACSAria (Becton Dickinson, San Jose, CA) (purity >94\%) after $24 \mathrm{~h}$ cocultures of BMDCs with polarized EC monolayers. Murine intestinal ECs were isolated from the small intestine or colon of C57/BL6J mice, using the protocol described above. A murine small intestinal EC line MODE-K (kindly provided by Dr D Kaiserlian ${ }^{34}$ ); CMT93, a mouse rectal carcinoma cell line (kindly provided by Dr D Artis Department of Pathobiology, University of Pennsylvania, Philadelphia); 4T1 invasive mouse mammary tumor cells (CRL-2539); and the NIH-3T3 cells (CRL-1658) (obtained from The American Type Culture Collection, Manassas, VA) were cultured in Iscove's modified Dulbecco's medium supplemented with $10 \%$ fetal bovine serum, $2 \mathrm{mmoll}^{-1}$ glutamine, $100 \mathrm{IU} \mathrm{ml}^{-1}$ penicillin, $100 \mu \mathrm{g} \mathrm{ml}^{-1}$ streptomycin, and $50 \mu \mathrm{moll}^{-1}$ 2-mercaptoethanol.

\section{DC conditioning and activation}

Supernatants of confluent MODE-K, CMT93, 4T1, or NIH-3T3 fibroblast cell lines, or supernatants collected after $24 \mathrm{~h}$ culture of primary IECs were used for DC conditioning. Alternatively, CMT93 cells were cultured for 78 hours in the upper chambers of Transwell filters $(3 \mu \mathrm{m}$ in pore diameter; Costar Europe, Badhoevedorp, The Netherlands) until a transepithelial resistance of $300 \Omega$ times per $\mathrm{cm}^{2}$ was achieved (polarized monolayer).

Murine BMDCs or splenic DCs were incubated for $24 \mathrm{~h}$ with medium alone or with cell line supernatants. In EC-DC contact-dependent interaction experiments, BMDCs were seeded for $24 \mathrm{~h}$ on the basolateral side of polarized monolayers of CMT93. In some of the experiments, MODE-K supernatants were pre-incubated with anti-TGF- $\beta$ antibody (clone 1D11, R\&D Systems, Minneapolis, MN) for $2 \mathrm{~h}$ at $37^{\circ} \mathrm{C}$. Alternatively, DCs were pre-incubated with LE540 (Wako Chemicals, Osaka, Japan) for $1 \mathrm{~h}$ at $37^{\circ} \mathrm{C}$ and then used for conditioning as described above. When cytokine secretion by BMDCs (EC-conditioned or control DCs) was examined, cells were activated for $6 \mathrm{~h}$ with $1 \mu \mathrm{g} \mathrm{ml}^{-1}$ LPS (Alexis Biochemicals, San Diego, CA), were washed, and cultured for additional $24 \mathrm{~h}$ in the complete medium. Culture supernatants were analyzed using ELISA (IL-2, IL-6, IL-10, and IL-12p70; R\&D Systems) according to the manufacturers' instructions.

\section{T-cell differentiation assays}

BMDCs were conditioned with MODE-K supernatants for $24 \mathrm{~h}$ or were FACS-separated into $\mathrm{CD}_{103}{ }^{+}$and $\mathrm{CD}_{103}{ }^{-}$after incubation with polarized EC monolayers, as described above. Then DCs were incubated with or without OVA ( $250 \mu \mathrm{g} \mathrm{ml}^{-1}$, Grade VI, Sigma-Aldrich) for $6 \mathrm{~h}$ and were placed in 96-well plates at a ratio of 1:10 (DC/T cell) with $\mathrm{CD} 4{ }^{+} \mathrm{CD} 25^{-}$ $\mathrm{T}$ cells purified according to the manufacturer's protocol (Miltenyi) from the spleens of OVA-specific OTII transgenic mice. For each condition, the experiment was carried out in a triplicate wells. For the experiments described in Supplementary Figure 1b, T cells were isolated from the spleens of DO11.10 SCID mice. CFSE-labeled CD ${ }^{+} \mathrm{CD} 25^{-}$ $\mathrm{T}$ cells were used for proliferation experiments. After 5 days of culture, supernatants were collected and were analyzed by ELISA for IFN- $\gamma$ and IL-17 (from R\&D Systems). IL-10, IL-5, and IL-13 production in the supernatants was analyzed using the cytokine bead array Flex Set System (BD Bioscience). In some cases, TGF- $\beta\left(2 \mathrm{ng} \mathrm{ml}^{-1}\right)$ was added at day 3 of the coculture. Cells from the cocultures were stained for CD4 (Pharmigen, San Jose, CA), CD25 (Pharmigen), $\alpha 4 \beta 7$ (BD Biosciences), and Foxp3 (e-Bioscience, San Diego, CA) after permeabilization. In some experiments, control or conditioned BMDCs were cocultured for 5 days with $\mathrm{CD}^{+}{ }^{+}$Foxp3-eGFP ${ }^{-}$T cells FACS sorted from the spleens of Foxp3-eGFP reporter mice. TGF- $\beta\left(2 \mathrm{ng} \mathrm{ml}^{-1}\right)$ was added at day 3 of the coculture.

\section{Suppression assay}

We isolated CD25 ${ }^{+}$T cells from the BMDC ( \pm MODE-K sn) T-cell cocultures and seeded them in a 1:1 ratio in a secondary coculture composed of responder CFSE-labeled CD4 ${ }^{+} \mathrm{T}$ cells $\left(1 \times 10^{5}\right)$, LPS-matured DCs $\left(2 \times 10^{4}\right)$, and plate-bound anti-CD3 $\left(0.5 \mu \mathrm{g} \mathrm{ml}^{-1}\right)$. As a positive control of the assay, $\mathrm{CD} 4{ }^{+} \mathrm{CD} 25^{+}$purified from mouse spleens were used, whereas for maximal proliferation $\mathrm{CD} 4{ }^{+} \mathrm{CD} 25^{-} \mathrm{T}$ cells from the mouse spleen were used. The proliferation of CFSE-labeled T cells from the second MLR was monitored by FACS.

\section{RT-PCR and quantitative real-time RT-PCR}

RNA was isolated from treated or untreated DCs or MODE-K cells, from FACS-sorted CD $103^{+}$MLN-DCs, primary IECs, colon, MLNs or spleen, and retro-transcribed. Real-time RT-PCR (reverse transcriptase-PCR) analyses were carried out in triplicate on the Applied Biosystems 7500 Fast Real-Time PCR System with the SYBR Green PCR kit as instructed by the manufacturer (Applied Biosystems, Carlsbad, CA). The amount of mRNA was normalized to the amount of $t b p$ or $r p l 32 \mathrm{mRNA}$. Samples were analyzed for the expression of Il23a, Il12a, aldh1a2, tgfb1 or tslp, using the primers listed in Supplementary Figure 6.

\section{Induction of DSS colitis, $\mathrm{T}_{\text {reg }}$-cell-adoptive transfer and histopathology}

To induce colitis, mice were housed in cages with drinking water supplemented with $2 \%$ (w/v) DSS (TdB Consultancy AB, Uppsala, Sweden) for 4 days. BMDCs were conditioned with MODE-K supernatants as described above. After washing, DCs were placed in 48-well plates at a ratio of $1: 10(\mathrm{DC} / \mathrm{T}$ cell $)$ with $\mathrm{CD} 4{ }^{+} \mathrm{CD} 25^{-} \mathrm{T}$ cells purified from the spleens of C57/BL6J mice and cocultured for 5 days. TGF- $\beta$ was added during the last 3 days of the coculture. Total or purified CD $25^{+}$cells $\left(1 \times 10^{6}\right)$ were injected intravenously $8 \mathrm{~h}$ before colitis induction. Body weight was measured daily as well as stool consistency and occult blood. At day 12 after colitis induction, mice were killed and intestines removed for gross examination, histopathology, and cytokine evaluation. Paraffinembedded colon tissues were sectioned and stained with hematoxylin and eosin for pathology assessment. Colon specimens $\left(1 \mathrm{~cm}^{2}\right)$ were collected (three per mice) divided into four groups and cultured in complete RPMI for $24 \mathrm{~h}$. Cytokines (TNF- $\alpha$, IFN- $\gamma$, and IL-6) were tested by ELISA in the supernatants.

\section{Statistical analysis}

Student's paired $t$-test was used to determine the statistical significance of the data. Significance was defined at $P<0.05$ (two-tailed test and twosample equal variance parameters). Statistic calculations were carried out by JMP 5.1 software (SAS Cary, NC).

SUPPLEMENTARY MATERIAL is linked to the online version of the paper at http://www.nature.com/mi

\section{ACKNOWLEDGMENTS}

This work was supported by the Crohn's and Colitis Foundation of America (CCFA to MR); by the Italian Association for Cancer Research (AIRC to MR); and by the European Research Council (ERC to MR). We thank Dr Yasmine Belkaid for providing eGFP-Foxp3 mice.

\section{DISCLOSURE}

The authors declared no conflict of interest.

(C) 2009 Society for Mucosal Immunology

\section{REFERENCES}

1. Kawai, T. \& Akira, S. TLR signaling. Semin. Immunol. 19, 24-32 (2007).

2. Lee, M.S. \& Kim, Y.J. Signaling pathways downstream of patternrecognition receptors and their cross talk. Annu. Rev. Biochem. 76, 447-480 (2007).

3. Harris, G., KuoLee, R. \& Chen, W. Role of Toll-like receptors in health and diseases of gastrointestinal tract. World J. Gastroenterol. 12, 2149-2160 (2006). 
4. Rescigno, M. et al. Dendritic cells express tight junction proteins and penetrate gut epithelial monolayers to sample bacteria. Nat. Immunol. 2, 361-367 (2001).

5. Chieppa, M., Rescigno, M., Huang, A.Y. \& Germain, R.N. Dynamic imaging of dendritic cell extension into the small bowel lumen in response to epithelial cell TLR engagement. J. Exp. Med. 203, 2841-2852 (2006).

6. Niess, J.H. et al. CX3CR1-mediated dendritic cell access to the intestinal lumen and bacterial clearance. Science 307, 254-258 (2005).

7. Kelsall, B.L. \& Rescigno, M. Mucosal dendritic cells in immunity and inflammation. Nat. Immunol. 5, 1091-1095 (2004).

8. Iwasaki, A. Mucosal dendritic cells. Annu. Rev. Immunol. 25, 381-418 (2007).

9. Coombes, J.L. et al. A functionally specialized population of mucosal CD103+ DCs induces Foxp3+ regulatory T cells via a TGF-\{beta $\}$ and retinoic acid dependent mechanism. J. Exp. Med. 204, 1757-1764 (2007).

10. Sun, C.M. et al. Small intestine lamina propria dendritic cells promote de novo generation of Foxp3T reg cells via retinoic acid. J. Exp. Med. 204, 1775-1785 (2007)

11. Cepek, K.L. et al. Adhesion between epithelial cells and T Iymphocytes mediated by E-cadherin and the alpha E beta 7 integrin. Nature 372, 190193 (1994)

12. Rimoldi, M. et al. Intestinal immune homeostasis is regulated by the crosstalk between epithelial cells and dendritic cells. Nat. Immunol. 6, 507-514 (2005)

13. Pandey, A. et al. Cloning of a receptor subunit required for signaling by thymic stromal lymphopoietin. Nat. Immunol. 1, 59-64 (2000).

14. Annacker, O. et al. Essential role for CD103 in the T cell-mediated regulation of experimental colitis. J. Exp. Med. 202, 1051-1061 (2005).

15. Smythies, L.E. et al. Human intestinal macrophages display profound inflammatory anergy despite avid phagocytic and bacteriocidal activity. J. Clin. Invest. 115, 66-75 (2005).

16. Denning, T.L., Wang, Y.C., Patel, S.R., Williams, I.R. \& Pulendran, B. Lamina propria macrophages and dendritic cells differentially induce regulatory and interleukin 17-producing T cell responses. Nat. Immunol. 8, 1086-1094 (2007).

17. Monteleone, I., Platt, A.M., Jaensson, E., Agace, W.W. \& Mowat, A.M. IL10-dependent partial refractoriness to Toll-like receptor stimulation modulates gut mucosal dendritic cell function. Eur. J. Immunol. 38, 15331547 (2008).

18. Iwasaki, A. \& Kelsall, B.L. Freshly isolated Peyer's patch, but not spleen, dendritic cells produce interleukin 10 and induce the differentiation of $T$ helper type 2 cells. J. Exp. Med. 190, 229-239 (1999).

19. Chirdo, F.G., Millington, O.R., Beacock-Sharp, H. \& Mowat, A.M. Immunomodulatory dendritic cells in intestinal lamina propria. Eur. J. Immunol. 35, 1831-1840 (2005).

20. Johansson-Lindbom, B. et al. Functional specialization of gut CD103+ dendritic cells in the regulation of tissue-selective T cell homing. J. Exp. Med. 202, 1063-1073 (2005)

21. Mora, J.R. et al. Generation of gut-homing lgA-secreting b cells by intestinal dendritic cells. Science 314, 1157-1160 (2006).
22. Uematsu, S. et al. Regulation of humoral and cellular gut immunity by lamina propria dendritic cells expressing Toll-like receptor 5. Nat. Immunol. 9, 769-776 (2008)

23. $\mathrm{Xu}, \mathrm{W}$. et al. Epithelial cells trigger frontline immunoglobulin class switching through a pathway regulated by the inhibitor SLPI. Nat. Immunol. 8, 294303 (2007).

24. He, B. et al. Intestinal bacteria trigger T cell-independent immunoglobulin $\mathrm{A}(2)$ class switching by inducing epithelial-cell secretion of the cytokine APRIL. Immunity 26, 812-826 (2007).

25. Mucida, D. et al. Reciprocal TH17 and regulatory $\mathrm{T}$ cell differentiation mediated by retinoic acid. Science 317, 256-260 (2007).

26. Benson, M.J., Pino-Lagos, K., Rosemblatt, M. \& Noelle, R.J. All-trans retinoic acid mediates enhanced $T$ reg cell growth, differentiation, and gut homing in the face of high levels of co-stimulation. J. Exp. Med. 204, 1765-1774 (2007).

27. Ivanov, I.I. et al. Specific microbiota direct the differentiation of IL-17producing T-helper cells in the mucosa of the small intestine. Cell Host Microbe 4, 337-349 (2008).

28. Atarashi, K. et al. ATP drives lamina propria $\mathrm{T}(\mathrm{H}) 17$ cell differentiation. Nature 455, 808-812 (2008).

29. Zaph, C. et al. Epithelial-cell-intrinsic IKK-beta expression regulates intestinal immune homeostasis. Nature 446, 552-556 (2007).

30. Read, S., Malmstrom, V. \& Powrie, F. Cytotoxic T lymphocyte-associated antigen 4 plays an essential role in the function of CD25(+)CD4(+) regulatory cells that control intestinal inflammation. J. Exp. Med. 192, 295-302 (2000).

31. Maloy, K.J., Salaun, L., Cahill, R., Dougan, G., Saunders, N.J. \& Powrie, F. CD4+CD25+ T(R) cells suppress innate immune pathology through cytokine-dependent mechanisms. J. Exp. Med. 197, 111-119 (2003).

32. Al-Shami, A. et al. A role for thymic stromal lymphopoietin in CD4+ T cell development. J. Exp. Med. 200, 159-168 (2004).

33. Bettelli, E. et al. Reciprocal developmental pathways for the generation of pathogenic effector $\mathrm{TH} 17$ and regulatory T cells. Nature 441, 235-238 (2006).

34. Vidal, K., Grosjean, I., Evillard, J.P., Gespach, C. \& Kaiserlian, D. Immortalization of mouse intestinal epithelial cells by the SV40-large T gene. Phenotypic and immune characterization of the MODE-K cell line. J. Immunol. Methods 166, 63-73 (1993).

35. Iwasaki, A. \& Kelsall, B.L. Unique functions of cd11b(+), cd8alpha(+), and double-negative Peyer's patch dendritic cells. J. Immunol. 166, 4884-4890 (2001)

36. Fujita, S. et al. Regulatory dendritic cells act as regulators of acute lethal systemic inflammatory response. Blood 107, 3656-3664 (2006).

37. Butler, M. et al. Modulation of dendritic cell phenotype and function in an in vitro model of the intestinal epithelium. Eur. J. Immunol. 36, 864-874 (2006)

38. Chen, W. et al. Conversion of peripheral CD4+CD25 - naive T cells to CD4+CD25+ regulatory T cells by TGF-beta induction of transcription factor Foxp3. J. Exp. Med. 198, 1875-1886 (2003).

39. Fantini, M.C., Becker, C., Monteleone, G., Pallone, F., Galle, P.R. \& Neurath, M.F. Cutting edge: TGF-beta induces a regulatory phenotype in CD4+CD25 - T cells through Foxp3 induction and down-regulation of Smad7. J. Immunol. 172, 5149-5153 (2004). 